\title{
Bipolar disorder in children and adolescents
}

\author{
Boris Birmaher ${ }^{1}$ \\ ${ }^{1}$ Department of Psychiatry, Western Psychiatric Institute and Clinic, University of Pittsburgh \\ School of Medicine, 3811 O'Hara Street, Bellefield Towers Room 612, Pittsburgh, PA 15213, \\ USA. birmaherb@upmc.edu
}

\begin{abstract}
Background-The existence of bipolar disorder (BP) in youth is controversial.

Methods-The current evidence regarding the diagnosis of BP in youth was reviewed.

Results-BP is a recurrent familial disorder that occurs in 1-3\% of youth, particularly in adolescents. Except for subsyndromal BP, the prevalence of BP-I is similar across most countries. Due to the child's immaturity, the presence of comorbid disorders, and divergent interpretations of manic symptomatology it is difficult to diagnose BP in youth. Youth with subsyndromal mania and family history of BP, are at high risk to develop BP-I and BP-II. Both the full and subsyndromal syndromal BP are associated with significant psychosocial difficulties and increased risk for use of substances, suicidality, legal problems, and services utilization.
\end{abstract}

Conclusion-BP disorder exists in youth, but it is difficult to diagnose. The recurrent nature and psychosocial morbidity associated with this illness during critical developmental stages calls for comprehensive longitudinal evaluation and accurate recognition and treatment because delays in treatment are associated with poor outcome.

\section{Keywords}

children; adolescents; bipolar disorder; diagnostic controversies; family history

\section{Introduction}

Tom is a 12-year-old boy whose parents sought psychiatric consultation because he experienced a one-month episode of depression which improved without intervention. Thereafter, he became very happy and silly, talkative, energetic, and hypersexual. At the same time, he slept only for few hours at night, was unable to sit still in class, his selfesteem was elevated, or irritable. Due to recurrent disruptive behaviors, Tom was suspended from school. He responded readily to treatment with a second-generation antipsychotic and returned to his regular academic and social activities. Discontinuation of the medication resulted in a recurrence of the depressive and later on, manic symptoms. Tom resumed the same medication and began psychotherapy and he has been asymptomatic for one year.

Amy is a 9-year-old girl who for the last 2 years has been experiencing intermittent $2-3$ day episodes of increased activity, silliness, poor concentration, increased creativeness and selfesteem, and lack of need for sleep without noticeable tiredness the next day. In addition, she has had periods lasting 3-5 weeks where she is more sullen, angry, sad, tired, tearful, distractible, and with less motivation and more defiant behaviors at home and at school. Amy was diagnosed with attention deficit hyperactive disorder (ADHD) and oppositional 
defiant disorder (ODD) and treated with individual and family psychotherapy and thereafter with stimulants, without response. After presenting to our clinic, it was decided to start psychotherapy and observe her mood using mood diaries and frequent communication with our clinic through visits, phone calls and emails. Six months later, it became clear that Amy was experiencing recurrent episodes of major depression that lasted between 3-8 weeks, interspersed with periods of normal mood or 3-4 days of hypomanic-like episodes. During the hypomanic episodes she was very fidgety, very happy and silly above what is expected for her age, disinhibited (talking to strangers, doing push-ups in the clinic's waiting room), very talkative, disorganized, and with less need for sleep. While in this mood, Amy described herself as being "on fast-forward". Treatment with mood stabilizers and psychotherapy resulted in normalization of her mood and behavior at school and at home.

As reviewed in this article, there is growing literature showing that similar to the examples of Tom and Amy, there are children and adolescents with symptoms that suggest bipolar disorder (BP). In fact, several studies across the world have consistently reported that up to $60 \%$ of adult patients with BP report the onset of their mood symptoms before age 21 years old (e.g., Baldessarini, Bolzani, Cruz, Jones, Lai, Lepri, Perez, Salvatore, Tohen, Tondo, \& Vieta, 2010; Chengappa, Kupfer, Frank, Houck, Grochocinski, Cluss, \& Stapf, 2003; Goodwin \& Jamison, 2007). Despite the above information and multiple studies that have shown that BP disorder can be reliably diagnosed in children and adolescents, the presence of BP in youth continues to be controversial and often discounted. Moreover, there are disagreements among clinicians within and among countries how to ascertain and interpret the symptoms of mania or hypomania in youth (Dubidka et al., 2008; Diler 2007; Diler \& Birmaher 2012). The main goal of this article is to summarize the current literature and complexities in diagnosing BP in youth with special emphasis on the areas of controversy. Throughout this article, unless specified, the word youth denotes both, children and adolescents.

\section{Clinical presentation}

$\mathrm{BP}$ is defined by the presence of recurrent episodes of mania or hypomania with and without episodes of depression. First, the symptoms and problems encountered in ascertaining symptoms of mania or hypomania will be discussed. Thereafter, the symptoms of major depression will be addressed.

\section{Mania/Hypomania}

Youth can be diagnosed with mania or hypomania using the existing DSM criteria for adults (APA, 2000; Axelson, Birmaher, Strober, Gill, Valeri, Chiappetta, Ryan, Leonard, Hunt, Iyengar, Bridge, \& Keller, 2006; Birmaher, Axelson, Pavaluri, 2007; Carlson, 2011; Findling, Youngstrom, Fristad, Birmaher, Kowatch, Arnold, Frazier, Axelson, Ryan, Demeter, Gill, Fields, Depew, Kennedy, Marsh, Rowles, \& Horwitz, 2010; Kowatch, Youngstrom, Danielyan, \& Findling, 2005; Youngstrom, Birmaher, \& Findling, 2008). However, the existing criteria must be used cautiously considering that the manic or hypomanic symptoms:

1. must exceed expectations for the normal developmental stage of the child or adolescent, particularly symptoms such as elation and grandiosity.

2. must cluster in episodes so that they either onset or intensify with the abnormal mood. However, as discussed in detail below, some investigators have questioned the need for episodicity (Mick, Biederman, Faraone, Murray, \& Wozniak, 2003).

3. cannot be mainly accounted for by other disorders such as ADHD or ODD (especially increased activity, agitation, irritability, distractibility, and 
talkativeness). If either of these other disorders exists, the mood symptoms must clearly worsen during the episode of mania or hypomania.

4. cannot be mainly explained by child's environmental or cultural context or the presence of any medical illness, or use of drugs or medications (e.g., corticosteroids).

5. must affect the functioning of the youth is several areas of functioning such as academic, family and friends. However, hypomania, particularly when is not severe, may improve the child's functioning (e.g., more outgoing, increased energy to do homework, and more creativity).

With some exceptions, the existing literature reports significant variations in the prevalence of each manic symptom, highlighting the problems identifying manic symptoms in youth (Axelson, et al., 2006; Carlson, 2011; Dubicka et al., 2008; Kowatch, et al., 2005; Stringaris and Santosh 2010; Youngstrom, et al., 2008). The discrepancies among investigators may be explained by methodological differences, the pre-conceptions of investigators and clinicians about the way that manic symptoms manifest in youth, difficulties differentiating some manic symptoms from normative mood/behaviors, and the overlap of these symptoms with other psychopathology. In addition, due to the children's cognitive and emotional immaturity, they might have difficulty expressing describing their mood symptoms and/or these symptoms may be modified by the developmental stage of the child. For example, the identification of elation, grandiosity, and or increased goal activity may be challenging from age-appropriate behavior in children. Elation can be difficult to ascertain because it is expected that youth will at times be overly happy, silly, and goofy spontaneously or triggered by certain situations (e.g. parties, visiting an amusement park). However, if these symptoms are recurrent, inappropriate for the context, beyond what is expected for the age of the child, and accompanied by other manic or hypomanic symptoms, elation needs to should be ruled considered as a potential symptom of a manic episode. Grandiosity is also a tricky symptom to diagnose in children because it is normal for them to overestimate their abilities and to believe that he/she is "the best" at a particular sport, smarter than others, or that he/she is or will be very important. Some children, particularly those with oppositional defiant or conduct disorders, will chronically believe that they are above needing to follow adults' rules and requests. Therefore, identifying a change from the child's usual behavior and self-image is key. Some examples that can raise the suspicion that the grandiosity is pathological include the following: a child who believes he/she is by far the best sports player, singer, student etc., despite clear evidence to the contrary; a child who repeatedly commands teachers, parents and coaches to do what they want despite that they are getting in trouble; a child thinking he/she has superpowers and acts upon these thoughts doing things that most kids of their age would not dare to do even if they were also fantasizing about similar issues (e.g., trying to fly from a tall tree or a third floor from a building, crossing the street without regard for traffic, not because of lack of attention or impulsivity, but because they believe nothing will happen to them). Finally, to be considered a manic symptom, increased goal activity in children has to be exaggerated, represent a change in functioning and be recognized by others as excessive for the developmental age of the child. For adolescents, with some exceptions (e.g., making many business deals for a kid who is still in school) the behaviors described for adults with mania are appropriate. For younger children, increased goal-activity can be hard to ascertain, particularly if they have ADHD. Some examples include a child with uncharacteristically periods of driven creative activity such as drawing, painting, writing or building things; the child who takes on many tasks simultaneously (e.g. flies through school work while playing video games, watching TV, and communicating with friends), starts devising elaborate and unrealistic plans for projects, trips or peer activities; and the child who exhibits driven activity to rearrange and redecorate his/her room, or to spontaneously complete many household chores well beyond 
expectations (clean most of the house, do lots of laundry, etc.) especially if the child typically does not engage in these activities or is performing them at unusual times such as late at night.

Another symptom that can be complicated to ascertain in youth, but when present, can help with the diagnosis of BP, is increased sexual activity. To be counted as a manic symptom, increased sexual activity must be inappropriate for the age of the child and not mainly accounted for by a history of sexual abuse, exposure to videos, TV or actual sex. For children, this can manifest as preoccupation with viewing or drawing naked people, provocative touching of the breasts, genital area or buttocks of others, intense and inappropriate kissing, or sexually explicit dancing (grabbing crotch, exposing genitals). Frequency, intensity and temporal association with elevated and/or irritable mood are key factors when assessing potential hypersexual behavior, as mild expressions of these behaviors could be normal if they are transient and do not impair functioning.

There are other important developmental differences between children and adolescents that impact symptom presentations. For example, children tend to have more rapid fluctuations in their mood, mixed presentations and behavior problems and separation anxiety than the adolescents. In contrast, adolescents have more distinct manic and depressive episodes, suicidality, substance abuse and panic disorder. Overall, children and adolescents have more mixed presentations and rapid changes in polarity of their mood episodes than the BP adults, explaining, at least in part, the difficulties diagnosing and treating them.

\section{Hypomania}

The symptoms of hypomania are of lesser duration and intensity than the ones of mania. According to the DSM-IV (APA, 2000), the symptoms of hypomania must last at least 4 days. However, studies in both youth and adults have shown that people with 2-3 days of symptoms do as poorly as those with 4 or more days, raising the question of the validity of the DSM duration criteria (Angst, Gamma, Benazzi, Ajdacic, Eich, \& Rossler, 2003; Axelson, Birmaher, Strober, Goldstein, Ha, Gill, Goldstein, Yen, Hower, Hunt, Liao, Iyengar, Dickstein, Kim, Ryan, Frankel, \& Keller, 2011; Vieta \& Suppes, 2008). While hypomanic, youth can sometimes function better and show increased creativity and productivity than when euthymic. However, recurrent hypomania can induce significant psychosocial impairment and be associated with increased risk for suicide, substance abuse, academic problems, and legal problems. Thus, it is important to always assess for the presence of hypomanic symptoms, particularly in youth with depression and to be careful not to assume that hypomanic-like symptoms are "normal".

\section{Major depression}

Similar to the symptoms of mania or hypomania, the symptoms of Major Depression (APA, 2000). in youth must exceed what it is considered normal for the child's developmental age, must cluster in episodes, and not be mainly accounted for by the presence of comorbid disorders.

As is also the case for assessing manic symptoms in youth, the child's cognitive and emotional immaturity may make it difficult to identify some of the symptoms of Major Depression. For example, younger children may not report feeling depressed, but bored or may appear as only irritable. A real intent to commit suicide can be masked because children may choose methods that in reality are not lethal, such as holding their breath or putting their head under water in the bathtub. Also, problems in describing their mood, together with the increased irritability and other symptoms of depression (e.g., fatigue, sleep problems), may make the child more likely to display behavior problems, rebel against parents and 
teachers (e.g., not doing homework), and exhibit low frustration tolerance and frequent temper outbursts. Depressed adolescents can be irritable, oppositional, befriend other teens who are also experiencing difficulties, get in trouble with the law, skip school and sometimes use substances. All these symptoms may be misinterpreted as behavioral disorders causing the symptoms of depression to be overlooked.

Children with MDD usually have less neurovegetative or melancholic symptoms than depressed adolescents or adults (Birmaher, Williamson, Dahl, Axelson, Kaufman, Dorn, \& Ryan, 2004; Yorbik, Birmaher, Axelson, Williamson, \& Ryan, 2004). Depressed adolescents appear to have more atypical symptomatology such as hypersomnia and increased appetite and weight gain than adults (Birmaher, et al., 2004). Symptoms like anhedonia are usually not as common as in depressed adults and can be selective to activities that require more mental effort. Youth with MDD may still be active in sports and music, but they do not enjoy these activities as much as before they became depressed. In addition, some youth, particularly those interested in doing well at school and those who are intelligent may continue to do well academically, but they may require more time and effort to maintain grades or finish homework when depressed.

The symptoms of depression may fluctuate more frequently and be more reactive in depressed youth compared to adults. Often, depressed children do not appear or feel depressed all the time. They can be depressed at school, but feel or look happy when they are with their friends or playing games. Thus, to consider MDD in youth, it is practical to evaluate what proportion of time (e.g., a week) they are depressed. In fact, some investigators have suggested that to consider the depression as significant they should be depressed at least 50\% of the time (Birmaher, et al., 2004; Yorbik, et al., 2004).

Finally, it is important to emphasize that there is consistent growing evidence that a substantial proportion of adults and youth with major depression have unrecognized subsyndromal manic symptoms (Angst, Azorin, Bowden, Perugi, Vieta, Gamma, Young, \& Group, 2011). These people usually have a poor prognosis and are resistant and/or adversely respond to treatment with antidepressants (Angst, et al., 2011; Maalouf, Porta, Vitiello, Emslie, Mayes, Clarke, Wagner, Asarnow, Spirito, Keller, Birmaher, Ryan, Shamseddeen, Iyengar, \& Brent, 2012).

\section{Subtypes of BP}

Similar to adults with BP, youth can be diagnosed with several subtypes of BP disorders including BP-I (periods of mania and major depression), BP-II (episodes of hypomania and major depression), Mixed episodes (symptoms of mania and depression occurring within the same 2-week time frame), cyclothymia (periods of hypomania and mild depressions), and BP-not otherwise specified (BP-NOS) (Axelson, et al., 2006; Birmaher, et al., 2007; Birmaher, et al., 2004; DelBello, Hanseman, Adler, Fleck, \& Strakowski, 2007; Findling, et al., 2010; Youngstrom, et al., 2008). BP-NOS is vaguely defined in the DSM, but basically children who do not have the required 4 days of hypomania or 7 days of mania or are short of the symptoms required for mania or hypomania with functional impairment are given this diagnosis. Nevertheless, to avoid overdiagnosing BP-NOS, some investigators have suggested that a minimum number of days (e.g., 2), symptoms (elation plus 3 symptoms or irritability plus 3 symptoms), number of episodes (e.g., at least 4 episodes), and clear change in functioning need to be present to diagnose BP-NOS (Axelson, et al., 2006; Axelson, et al., 2011). In fact, youth fulfilling these criteria have as much morbidity, comorbid disorders, suicidality, substance abuse, and family history of mood disorders as youth with BP-I (Axelson, et al., 2006; Axelson, et al., 2011). It is important to emphasize that this subtype of BP is not related to the phenotype called Severe Mood Dysregulation (SMD) or the new 
proposed Disruptive Mood Dysregulation Disorder (DMMD) (Axelson, Findling, Fristad, Kowatch, Youngstrom, Horwitz, Arnold, Frazier, Ryan, Demeter, Gill, Hauser-Harrington, Depew, Kennedy, Gron, Rowles, \& Birmaher, in press; Axelson, et al., 2011; Leibenluft, 2011). These latter conditions are chronic and not episodic and appear to correspond to youth with severe ODD (Axelson, et al., in press; Axelson, Birmaher, Findling, Fristad, Kowatch, Youngstrom, Arnold, Goldstein, Goldstein, Chang, Delbello, Ryan, \& Diler, 2011a; Leibenluft, 2011).

At the onset of the illness, BP can be manifested with any polarity (depressed, manic, hypomanic), but it appears that more frequently it presents with depression (Birmaher, 2007). This may create a challenge for clinicians because treatment with antidepressants may trigger an episode of mania in a child who is predisposed to develop BP. Currently there are nonclinical or biological tests than can help to distinguish between unipolar and BP depressions. However, some studies have suggested that depressed youth with a family history of BP, pharmacologically induced mania/hypomania, and/or presence of depression with psychosis are at high risk to develop BP (Akiskal, 1998; Geller, Fox, \& Clark, 1994; Strober \& Carlson, 1982). Thus, these youth need to be monitored more carefully when administered antidepressants. Moreover, several studies have consistently shown that 30\%$40 \%$ of adults and youth with unipolar MDD may have subtle symptoms of mania or hypomania that often go under diagnosed (Angst, et al., 2011; Maalouf, et al., 2012; Zimmermann, Bruckl, Nocon, Pfister, Lieb, Wittchen, Holsboer, \& Angst, 2009). Compared with unipolar MDD without BP symptoms, e patients with "hidden' bipolarity have younger onset age, more depressive episodes less response to antidepressants and higher risk to develop BP. Also, they have more frequent suicide attempts, comorbidity anxiety, problems controlling their impulses, substance abuse, family members with BP, and worse course.

Although not a specific subtype of BP, like adults, youth can experience symptoms of psychosis (presence of hallucinations and/or delusions) while manic or depressed (Birmaher, et al., 2007; Youngstrom, et al., 2008). These symptoms may also be present during the depressive phase of the illness. Perhaps due to their cognitive immaturity, children tend to have more hallucinations than delusions whereas adolescents tend to have more delusions than hallucinations (Birmaher, 2007). Up to $40 \%$ of the youth with BP may have psychotic symptoms (hallucinations or delusions) with rates depending on the source of the sample and instruments used to ascertain these symptoms (Axelson, et al., 2006; Birmaher, Axelson, Goldstein, Strober, Gill, Hunt, Houck, Ha, Iyengar, Kim, Yen, Hower, Esposito-Smythers, Goldstein, Ryan, \& Keller, 2009; Carlson, Kotov, Chang, Ruggero, \& Bromet, 2012; Kowatch, et al., 2005).

\section{Comorbidity}

Bipolar disorder is often accompanied by other psychiatric disorders (20\%-80\%), particularly disruptive behavior disorders, ADHD, anxiety disorders, and in adolescents, substance use disorders (Axelson, et al., 2006; Goldstein, Strober, Birmaher, Axelson, Esposito-Smythers, Goldstein, Leonard, Hunt, Gill, Iyengar, Grimm, Yang, Ryan, \& Keller, 2008; Kowatch, Fristad, Birmaher, Wagner, Findling, \& Hellander, 2005a; Kowatch, et al., 2005; Sala, Axelson, Castro-Fornieles, Goldstein, Ha, Liao, Gill, Iyengar, Strober, Goldstein, Yen, Hower, Hunt, Ryan, Dickstein, Keller, \& Birmaher, 2010). However, the rates of these disorders in very heterogeneous, depending on the methods utilized to ascertain them and the sample studied, as well as the age of the sample. For example, the prevalence of BP is higher in clinical versus community samples. ADHD and oppositional defiant disorder are more common in children with BP, while rates of conduct and substance use disorders are greater in adolescents. The presence of these disorders conveys a challenge for the differential diagnoses because some of the symptoms, especially those of ADHD, 
overlap with the symptoms of mania or hypomania. Furthermore, comorbid disorders influence the response to treatment and the prognosis for BP, indicating the need to accurately identify these youth and to effectively treat them.

Some clinical tips that may be helpful for the differential diagnoses between BP and ADHD and ODD are presented in tables 1 and 2.

\section{Controversies regarding the criteria for diagnosing BP in youth}

There are four main controversies regarding the diagnosis of BP in youth. (1) Can mania present with irritability without elation? (2) Can mania present without episodes?; (3) Does BP in youth present with very rapid cycling?; and (4) Is BP over diagnosed in youth, particularly in the USA?

\section{Can mania present with irritability without elation?}

It has been suggested that mania in youth is mainly manifested by irritability and rarely with elation (Mick, et al., 2003). However, most of the studies have shown that elation is a common symptom of mania in youth and that mania rarely manifests itself with only elation or only irritability, but with both (Carlson, 2007; Hunt, Birmaher, Leonard, Strober, Axelson, Ryan, Yang, Gill, Dyl, Esposito-Smythers, Swenson, Goldstein, Goldstein, Stout, \& Keller, 2009; Merikangas, Cui, Kattan, Carlson, Youngstrom, \& Angst, 2012). In any case, mania should not be diagnosed when irritability is not accompanied by the other symptoms of mania, and when it is not episodic (Axelson, et al., 2011; Birmaher, et al., 2007; Carlson, 2007; Carlson, Potegal, Margulies, Gutkovich, \& Basile, 2009; Leibenluft, 2011; Stringaris 2011).

Nevertheless, it is important to emphasize that perhaps irritability in the context of family history of BP may be an indicator that the youth is at risk to develop BP, but longitudinal studies are needed to corroborate this.

\section{Can mania present without episodes?}

Although some have suggested that BP in youth is manifested by chronic symptoms without episodes (Mick, et al., 2003) most investigators have shown that, similar to adults, mania is manifested episodically (Birmaher, 2007; Birmaher, et al., 2009; Leibenluft, 2011). Furthermore, cases of chronic irritability without clear episodicity seems to be more associated with ADHD and disruptive disorders than BP or the SMD phenotype (Axelson, et al., 2011; Carlson, 2007; Stringaris, 2011; Stringaris, Cohen, Pine, \& Leibenluft, 2009). Thus, it is important to follow these youth with probable symptoms of BP longitudinally in order to clearly document the presence of episodes.

\section{Does BP in youth present with very rapid cycling?}

The DSM and the ICD criteria define rapid cycling as at least four mood episodes (major depression, mania, mixed, or hypomanic) of a mood disturbance in a 12-month period (APA, 2000). Some authors have suggested that BP youths have very rapid cycling (Geller \& Cook, 2000). Using these criteria, it appears that youth with BP are more prone to rapid cycling than adults with BP. However, it seems that there is some confusion between having recurrent full-syndromal mood episodes and experiencing mood variations within an episode (Birmaher, et al., 2009). For example, during an episode of depression children may be depressed, irritable, euthymic or sometimes even happy. These children have fluctuation in their mood during the same episode, but they do not have separate mood episodes. This misunderstanding has given origin to the concept of "ultradian cycling" (Geller \& Cook, 
2000) and sometimes contributes to the misdiagnosing youth with BP, when in fact they may be experiencing mood lability in the context of other non-mood disorders.

\section{Is BP over-diagnosed in youth, particularly in the US?}

Recent studies have shown sharp increases in the rates in the diagnosis of BP in youth, raising the possibility that BP is being over-diagnosed, especially in the US (Blader \& Carlson, 2007; Moreno, Laje, Blanco, Jiang, Schmidt, \& Olfson, 2007). Before the diagnosis of BP, most adolescents were already diagnosed with depressive disorders, and most children with disruptive behavior disorders or ADHD, and they were already receiving treatment with psychotropic medications (stimulants, antidepressants and/or antipsychotics) (Olfson, Crystal, Gerhard, Huang, \& Carlson, 2009). Moreover, many did not continued to carry the diagnosis of BP suggesting that the diagnosis of BP was given tentatively to youth with severe psychopathology.

A meta-analysis and other recent studies reported that the prevalence of BP spectrum disorders in youth is on average $1.8 \%$ and for BP-I 1.2\%, with rates of BP-I being consistent among most countries (e.g., US and UK) (Kozloff, Cheung, Schaffer, Cairney, Dewa, Veldhuizen, Kurdyak, \& Levitt, 2010; Merikangas, et al., 2012; Stringaris and Santosh 2010; Van Meter, Moreira, \& Youngstrom, 2011). In contrast, the prevalence of subsyndromal cases, seems to be higher is the US (up to 6.7\%) when compared with other countries $(2.4 \%)$. The results of all of these studies suggest that: 1) the prevalence of BP-I in youth is similar to the current prevalence estimates of BP-I in adults (e.g., Kessler, Avenevoli, Costello, Georgiades, Green, Gruber, He, Koretz, McLaughlin, Petukhova, Sampson, Zaslavsky, \& Merikangas, 2012); 2) the rates of BP increase after puberty; 3) despite that $\mathrm{BP}$ is being diagnosed more commonly, the prevalence of BP in youth in the community apparently is not increasing. Moreover, the increase in diagnosis of BP in youth is not higher that that the increase in the diagnosis of depression; 4) the number of youth treated for BP appears to lag far behind the population prevalence; and 5) the main difference in the prevalence of BP between the US and other countries is the increased prevalence of subsyndromal BP or BP-NOS, but not BP-I. The difference in subsyndromal BP may be attributable to the imprecise DSM-IV definition of BP-NOS and the issues regarding the inclusion of youth with only irritability, non-episodic BP or 'ultradian' cycles discussed above. However, it is also possible that in some studies, the presence of subsyndromal BP was overlooked. Thus, as described below, more studies evaluating the diagnostic criteria and the significance of episodic subsyndromal manic symptomatology are warranted (Axelson, et al., 2011).

\section{If pediatric BP is a valid disorder, it should specifically run in families}

Most studies have demonstrated that, even after controlling for confounding factors (e.g., non-BP parental psychopathology), offspring of parents with BP are at higher risk to develop BP than offspring of control parents (Chang, Steiner, \& Ketter, 2003; DelBello \& Geller, 2001; Henin, Biederman, Mick, Sachs, Hirshfeld-Becker, Siegel, McMurrich, Grandin, \& Nierenberg, 2005; Hillegers, Reichart, Wals, Verhulst, Ormel, \& Nolen, 2005). In general, when one parent has BP the risk of the child having BP is between 10 and 25\% with higher rates when both parents have BP (Goldstein, Shamseddeen, Axelson, Kalas, Monk, Brent, Kupfer, \& Birmaher, 2010; Goodwin \& Jamison, 2007). The risk of developing BP increases after puberty (Birmaher, Axelson, Monk, Kalas, Goldstein, Hickey, Obreja, Ehmann, Iyengar, Shamseddeen, Kupfer, \& Brent, 2009a; Duffy, 2010; Hillegers, et al., 2005). In the same way, other studies have shown that the first-degree relatives of youth with BP are at higher risk to have BP when compared with families of healthy children or children with MDD or ADHD (Geller, Tillman, Bolhofner, Zimerman, Strauss, \& Kaufmann, 2006; Wozniak, Faraone, Mick, Monuteaux, Coville, \& Biederman, 2010). The 
above research as well as studies of twins (Taylor, Faraone, \& Tsuang, 2002) have demonstrated that BP specifically runs in families and it is one of the most hereditable psychiatric disorders.

It is important to mention that offspring of parents with BP are also at high risk to develop other disorders, especially unipolar major depression, and disruptive and anxiety disorders. Thus, a child of a parent with BP who has behavior problems, increased irritability, or sadness does not necessarily have BP.

\section{Course and outcome}

Although the rates of recovery from index episodes are high (70\%-100\%), of those who recover, up to $80 \%$ will experience one or more syndromal recurrences over a period of 2 to 5 years, particularly depressive episodes, and multiple subsyndromal recurrences (Birmaher, 2007; Birmaher, et al., 2009; Carlson, et al., 2012; DelBello, et al., 2007; Diler 2007; Geller, Tillman, Bolhofner, \& Zimerman, 2008).

An analysis of the percentage of the follow-up time spent asymptomatic or with clinically significant mood symptomatology showed that youth with BP spent approximately $20 \%$ of the time with full syndromal symptoms, $40 \%$ of the time with subsyndromal symptoms, and $40 \%$ of the time euthymic (Birmaher, et al., 2009). Most of the symptoms were of depressive or mixed type. Similar findings have been reported in other longitudinal studies (Birmaher, 2007; Carlson, et al., 2012; DelBello, et al., 2007; Geller, et al., 2008).

Compared with adult BP studies, youth with BP spend more time symptomatic and with mixed/rapid cycling, subsyndromal symptoms, and with more mood changes (Birmaher, et al., 2009). These findings explain, at least in part, the difficulties diagnosing and treating youth with BD.

Several factors have been associated with worse course and outcome. These include early age of onset, long duration of illness, low socioeconomic status, mixed or rapid cycling episodes, psychosis, subsyndromal mood symptoms, comorbid disorders, exposure to negative life events, high expressed-emotion, and family psychopathology (Birmaher, 2007; Birmaher, et al., 2009; Carlson, et al., 2012; DelBello, et al., 2007).

Due to the recurrent nature of this illness and its effects on the youth's mood and behaviors, BP is associated with significant negative psychosocial consequences, family, interpersonal, academic, and legal problems, and increased risk for suicidality and substance abuse (Bella, Goldstein, Axelson, Obreja, Monk, Hickey, Goldstein, Brent, Diler, Kupfer, Sakolsky, \& Birmaher, 2011; Birmaher, et al., 2009; Birmaher, et al., 2007; DelBello, et al., 2007; Goldstein, et al., 2008; Goldstein, Birmaher, Axelson, Goldstein, Gill, Esposito-Smythers, Ryan, Strober, Hunt, Keller, \& Goldstein, 2009; Goldstein, Ha, Axelson, Goldstein, Liao, Gill, Ryan, Yen, Hunt, Hower, Keller, Strober, \& Birmaher, 2012). Therefore, the need for early identification, accurate diagnosis, and ongoing psychosocial and pharmacological treatments is crucial.

Youth with subsyndromal mania (BP-NOS), particularly those with family history of BP are at risk to convert in to BP-I or II with rates of conversion of $45 \%$ (BP-I: $23 \%$ and BP-II: $22 \%$ ) (Axelson, et al., 2011). Youth with BP-NOS have as much psychosocial impairment and risk for suicidality and substance abuse as the children with full syndromal BP-I, indicating the need to develop treatments for this population and hopefully protocols to prevent the development of full syndromal BP-I/II. 


\section{Conclusions}

BP spectrum disorder is a familial disorder that occurs in 1-3\% of children and adolescents, with increased rates of onset during the adolescent years. The symptoms of BP, especially those for BP-I, can be reliably diagnosed in youth. However, making a diagnosis of BP presents several challenges because the disagreement regarding the definition of episodes, the ascertaining and interpretation of symptoms like elation and grandiosity, and the difficulties to distinguish certain manic symptoms from developmentally appropriate behavior in children. In addition, there are developmental differences in the clinical presentation of BP, with older adolescents having more classic manic and depressive symptoms and distinct episodes, whereas children with BP tend to have more mixed and rapid cycling presentations. Finally, the high rates of comorbid disorders with overlapping symptoms with mania make the diagnosis more difficult. Thus, the need for more studies across countries to carefully and taking into account the development of the child, define the key symptoms of mania in youth and how to differentiate them from other disorders. Moreover, given the controversies and the consequences associated with the diagnosis of BP in youth, it is crucial to perform comprehensive longitudinal evaluation of youth for whom $\mathrm{BP}$ is suspected before making the final diagnosis of BP.

BP is manifested by recurrent syndromal, and more frequently subsyndromal episodes, especially depressions. Youth with subsyndromal mania, particularly if there is family history of BP, are at high risk to develop full syndromal episodes. Both the full syndromal and the subclinical BP are associated with significant psychosocial difficulties and increased risk for academic problems, family conflicts, use of substances, suicidality, legal problems, increased utilization health care services, and economic problems. In fact, the World Health Organization reported that $\mathrm{BP}$ is the $4^{\text {th }}$ leading cause of disability among adolescents worldwide.

The recurrent nature and psychosocial morbidity associated with this illness during critical developmental stages calls for its prompt recognition and treatment, particularly since delays in appropriate diagnosis and treatment are associated with less likelihood of full recovery and poor outcome.

Although it is accurate that some youth are being misdiagnosed with BP, it is also true that there are children and adolescents whose BP is unnoticed or misdiagnosed. Thus, until the criteria for diagnosing BP in youth is better clarified and until more objective ways to diagnose BP are identified (e.g., biomarkers), clinicians will continue to be confronted with the dilemma of using more over-inclusive or excessively conservative criteria to diagnose $\mathrm{BP}$ in youth. Each approach has its advantages and disadvantages. Using broader criteria has the potential to misdiagnose children with $\mathrm{BP}$, a diagnosis with long-term prognostic and social implications, and expose them to medications with little benefit and unnecessary side effects. In contrast, using a very strict diagnostic criteria or in extreme cases, denying the existence of BP in youth, may exclude children and adolescents with real BP from the proper treatment and as a consequence obstruct their normal development, increase the risk for the serious consequences of BP (e.g., suicidal behavior, increase risk for substance abuse, and legal problems), and expose them to medications and other non-efficacious treatments that can worsen the course of BP.

\section{Acknowledgments}

B.B. has received research support from the National Institutes of Mental Health. He receives book royalties from Random House, Inc., and Lippincott Williams \& Wilkins. This review article was invited by the journal following the presentation of some of the material as the 2011 Emmanuel Miller Lecture (ACAMH, June 2011, London), for which B.B. received travelling expenses; the final manuscript was subject to full peer review. 


\section{References}

Akiskal HS. The childhood roots of bipolar disorder. Journal of Affective Disorders. 1998; 51(2):7576. [PubMed: 10743839]

Angst J, Azorin J-M, Bowden CL, Perugi G, Vieta E, Gamma A, Young AH, Group BS. Prevalence and characteristics of undiagnosed bipolar disorders in patients with a major depressive episode: the BRIDGE study. Archives of General Psychiatry. 2011; 68(8):791-798. [PubMed: 21810644]

Angst J, Gamma A, Benazzi F, Ajdacic V, Eich D, Rossler W. Toward a re-definition of subthreshold bipolarity: epidemiology and proposed criteria for bipolar-II, minor bipolar disorders and hypomania. Journal of Affective Disorders. 2003; 73(1-2):133-146. [see comment]. [PubMed: 12507746]

APA. Diagnostic and Statistical Manual of Mental Disorders. 4 th edition. Washington, DC: Author; 2000.

Axelson D, Birmaher B, Strober M, Gill MK, Valeri S, Chiappetta L, Ryan N, Leonard H, Hunt J, Iyengar S, Bridge J, Keller M. Phenomenology of children and adolescents with bipolar spectrum disorders. Archives of general psychiatry. 2006; 63(10):1139-1148. [PubMed: 17015816]

Axelson D, Findling RL, Fristad MA, Kowatch RA, Youngstrom EA, Horwitz SM, Arnold LE, Frazier TW, Ryan N, Demeter C, Gill MK, Hauser-Harrington JC, Depew J, Kennedy SM, Gron BA, Rowles BM, Birmaher B. Examining the proposed disruptive mood dysregulation disorder diagnosis in the Longitudinal Assessment of Manic Symptoms Study. Journal of Clinical Psychiatry. (in press).

Axelson DA, Birmaher B, Findling RL, Fristad MA, Kowatch RA, Youngstrom EA, Arnold EL, Goldstein BI, Goldstein TR, Chang KD, Delbello MP, Ryan ND, Diler RS. Concerns regarding the inclusion of temper dysregulation disorder with dysphoria in the Diagnostic and Statistical Manual of Mental Disorders, Fifth Edition. Journal of Clinical Psychiatry. 2011a; 72(9):1257-1262. [PubMed: 21672494]

Axelson DA, Birmaher B, Strober MA, Goldstein BI, Ha W, Gill MK, Goldstein TR, Yen S, Hower H, Hunt JI, Liao F, Iyengar S, Dickstein D, Kim E, Ryan ND, Frankel E, Keller MB. Course of subthreshold bipolar disorder in youth: diagnostic progression from bipolar disorder not otherwise specified. Journal of the American Academy of Child and Adolescent Psychiatry. 2011; 50(10): 1001-1016. e1003. [PubMed: 21961775]

Baldessarini RJ, Bolzani L, Cruz N, Jones PB, Lai M, Lepri B, Perez J, Salvatore P, Tohen M, Tondo L, Vieta E. Onset-age of bipolar disorders at six international sites. Journal of Affective Disorders. 2010; 121(1-2):143-146. [PubMed: 19560827]

Bella T, Goldstein T, Axelson D, Obreja M, Monk K, Hickey MB, Goldstein B, Brent D, Diler RS, Kupfer D, Sakolsky D, Birmaher B. Psychosocial functioning in offspring of parents with bipolar disorder. Journal of Affective Disorders. 2011; 133(1-2):204-211. [PubMed: 21463899]

Birmaher B. Longitudinal course of pediatric bipolar disorder. The American journal of psychiatry. 2007; 164(4):537-539. [PubMed: 17403961]

Birmaher B, Axelson D, Goldstein B, Strober M, Gill MK, Hunt J, Houck P, Ha W, Iyengar S, Kim E, Yen S, Hower H, Esposito-Smythers C, Goldstein T, Ryan N, Keller M. Four-year longitudinal course of children and adolescents with bipolar spectrum disorders: the Course and Outcome of Bipolar Youth (COBY) study. The American journal of psychiatry. 2009; 166(7):795-804.

[PubMed: 19448190]

Birmaher B, Axelson D, Monk K, Kalas C, Goldstein B, Hickey MB, Obreja M, Ehmann M, Iyengar S, Shamseddeen W, Kupfer D, Brent D. Lifetime psychiatric disorders in school-aged offspring of parents with bipolar disorder: the Pittsburgh Bipolar Offspring study. Archives of General Psychiatry. 2009a; 66(3):287-296. [PubMed: 19255378]

Birmaher, B.; Axelson, D.; Pavaluri, M. Bipolar Disorder. In: Martin, M Andrés, MD; Volkmar, Fred R., MD; Lewis, Melvin, MB, BS, editors. Lewis' Child and Adolescent Psychiatry: A Comprehensive Textbook. 4th ed.. London: Lippincott Williams \& Wilkins (LWW); 2007.

Birmaher B, Williamson DE, Dahl RE, Axelson DA, Kaufman J, Dorn LD, Ryan ND, Birmaher B, Williamson DE, Dahl RE, Axelson DA, Kaufman J, Dorn LD, Ryan ND. Clinical presentation and course of depression in youth: does onset in childhood differ from onset in adolescence? Journal of 
the American Academy of Child \& Adolescent Psychiatry. 2004; 43(1):63-70. [PubMed: 14691361]

Blader JC, Carlson GA. Increased rates of bipolar disorder diagnoses among U.S. child, adolescent, and adult inpatients, 1996-2004. Biological Psychiatry. 2007; 62(2):107-114. [PubMed: 17306773]

Carlson GA. Who are the children with severe mood dysregulation a.k.a. "rages"? American Journal of Psychiatry. 2007; 164(8):1140-1142. [PubMed: 17671272]

Carlson GA. Will the child with mania please stand up? British Journal of Psychiatry. 2011; 198(3): 171-172. [PubMed: 21357873]

Carlson GA, Kotov R, Chang S-W, Ruggero C, Bromet EJ. Early determinants of four-year clinical outcomes in bipolar disorder with psychosis. Bipolar Disorders. 2012; 14(1):19-30. [PubMed: 22329469]

Carlson GA, Potegal M, Margulies D, Gutkovich Z, Basile J. Rages--what are they and who has them? Journal of Child and Adolescent Psychopharmacology. 2009; 19(3):281-288. [PubMed: 19519263]

Chang K, Steiner H, Ketter T. Studies of offspring of parents with bipolar disorder. American Journal of Medical Genetics Part C, Seminars in Medical Genetics. 2003; 123(1):26-35.

Chengappa KN, Kupfer DJ, Frank E, Houck PR, Grochocinski VJ, Cluss PA, Stapf DA. Relationship of birth cohort and early age at onset of illness in a bipolar disorder case registry. American Journal of Psychiatry. 2003; 160(9):1636-1642. [PubMed: 12944339]

DelBello MP, Geller B. Review of studies of child and adolescent offspring of bipolar parents. Bipolar Disorders. 2001; 3(6):325-334. [PubMed: 11843782]

DelBello MP, Hanseman D, Adler CM, Fleck DE, Strakowski SM. Twelve-month outcome of adolescents with bipolar disorder following first hospitalization for a manic or mixed episode. American Journal of Psychiatry. 2007; 164(4):582-590. [see comment]. [PubMed: 17403971]

Diler, RS. Pediatric Bipolar Disorder: A Global Perspective. New York: Nova Science Publishers, Inc.; 2007.

Diler, RS.; Birmaher, B. Bipolar disorder in children and adolescents. In: Rey, JM., editor. IACAPAP e-Textbook of Child and Adolescent Mental Health. Geneva: International Association for Child and Adolescent Psychiatry and Allied Professions; 2012. Available at: http://iacapap.org/wpcontent/uploads/E.2-BIPOLAR-072012.pdf.

Dubicka B, Carlson GA, Vail A, Harrington R. Prepubertal mania: diagnostic differences between US and UK clinicians. European Child and Adolescent Psychiatry. 2008; 17:153-161. [PubMed: 17876503]

Duffy A. The early natural history of bipolar disorder: what we have learned from longitudinal highrisk research. Canadian Journal of Psychiatry - Revue Canadienne de Psychiatrie. 2010; 55(8): 477-485. [PubMed: 20723275]

Findling RL, Youngstrom EA, Fristad MA, Birmaher B, Kowatch RA, Arnold LE, Frazier TW, Axelson D, Ryan N, Demeter CA, Gill MK, Fields B, Depew J, Kennedy SM, Marsh L, Rowles BM, Horwitz SM. Characteristics of children with elevated symptoms of mania: the Longitudinal Assessment of Manic Symptoms (LAMS) study. The Journal of clinical psychiatry. 2010; 71(12): 1664-1672. [PubMed: 21034685]

Geller B, Cook EH Jr. Ultradian rapid cycling in prepubertal and early adolescent bipolarity is not in transmission disequilibrium with val/met COMT alleles. Biological psychiatry. 2000; 47(7):605609. [PubMed: 10745052]

Geller B, Fox LW, Clark KA. Rate and predictors of prepubertal bipolarity during follow-up of 6- to 12-year-old depressed children. Journal of the American Academy of Child \& Adolescent Psychiatry. 1994; 33(4):461-468. [PubMed: 8005898]

Geller B, Tillman R, Bolhofner K, Zimerman B. Child bipolar I disorder: prospective continuity with adult bipolar I disorder; characteristics of second and third episodes; predictors of 8-year outcome. Arch Gen Psychiatry. 2008; 65(10):1125-1133. [PubMed: 18838629]

Geller B, Tillman R, Bolhofner K, Zimerman B, Strauss NA, Kaufmann P. Controlled, blindly rated, direct-interview family study of a prepubertal and early-adolescent bipolar I disorder phenotype: 
morbid risk, age at onset, and comorbidity. Archives of General Psychiatry. 2006; 63(10):11301138. [see comment]. [PubMed: 17015815]

Goldstein BI, Shamseddeen W, Axelson DA, Kalas C, Monk K, Brent DA, Kupfer DJ, Birmaher B. Clinical, demographic, and familial correlates of bipolar spectrum disorders among offspring of parents with bipolar disorder. Journal of the American Academy of Child and Adolescent Psychiatry. 2010; 49(4):388-396. [PubMed: 20410731]

Goldstein BI, Strober MA, Birmaher B, Axelson DA, Esposito-Smythers C, Goldstein TR, Leonard H, Hunt J, Gill MK, Iyengar S, Grimm C, Yang M, Ryan ND, Keller MB. Substance use disorders among adolescents with bipolar spectrum disorders. Bipolar Disorders. 2008; 10(4):469-478. [PubMed: 18452443]

Goldstein TR, Birmaher B, Axelson D, Goldstein BI, Gill MK, Esposito-Smythers C, Ryan ND, Strober MA, Hunt J, Keller M, Goldstein TR. Psychosocial functioning among bipolar youth. Journal of Affective Disorders. 2009; 114(1-3):174-183. [PubMed: 18715651]

Goldstein TR, Ha W, Axelson DA, Goldstein BI, Liao F, Gill MK, Ryan ND, Yen S, Hunt J, Hower H, Keller M, Strober M, Birmaher B. Predictors of Prospectively Examined Suicide Attempts Among Youth With Bipolar Disorder Predictors of Suicide Attempts. Archives of general psychiatry. 2012:1-10. [PubMed: 22605542]

Goodwin, FK.; Jamison, K. Manic-Depressive Illness: bipolar disorders and recurrent depression. 2nd ed.. New York, N.Y: Oxford University Press; 2007.

Henin A, Biederman J, Mick E, Sachs GS, Hirshfeld-Becker DR, Siegel RS, McMurrich S, Grandin L, Nierenberg AA. Psychopathology in the offspring of parents with bipolar disorder: a controlled study. Biological Psychiatry. 2005; 58(7):554-561. [PubMed: 16112654]

Hillegers MH, Reichart CG, Wals M, Verhulst FC, Ormel J, Nolen WA. Five-year prospective outcome of psychopathology in the adolescent offspring of bipolar parents. Bipolar disorders. 2005; 7(4):344-350. [PubMed: 16026487]

Hunt J, Birmaher B, Leonard H, Strober M, Axelson D, Ryan N, Yang M, Gill M, Dyl J, EspositoSmythers C, Swenson L, Goldstein B, Goldstein T, Stout R, Keller M. Irritability without elation in a large bipolar youth sample: frequency and clinical description. Journal of the American Academy of Child and Adolescent Psychiatry. 2009; 48(7):730-739. [PubMed: 19465878]

Kessler RC, Avenevoli S, Costello EJ, Georgiades K, Green JG, Gruber MJ, He J-p, Koretz D, McLaughlin KA, Petukhova M, Sampson NA, Zaslavsky AM, Merikangas KR. Prevalence, persistence, and sociodemographic correlates of DSM-IV disorders in the National Comorbidity Survey Replication Adolescent Supplement. Archives of General Psychiatry. 2012; 69(4):372380. [PubMed: 22147808]

Kowatch RA, Fristad M, Birmaher B, Wagner KD, Findling RL, Hellander M. Treatment guidelines for children and adolescents with bipolar disorder. Journal of the American Academy of Child and Adolescent Psychiatry. 2005a; 44(3):213-235. [PubMed: 15725966]

Kowatch RA, Youngstrom EA, Danielyan A, Findling RL. Review and meta-analysis of the phenomenology and clinical characteristics of mania in children and adolescents. Bipolar disorders. 2005; 7(6):483-496. [PubMed: 16403174]

Kozloff N, Cheung AH, Schaffer A, Cairney J, Dewa CS, Veldhuizen S, Kurdyak P, Levitt AJ. Bipolar disorder among adolescents and young adults: results from an epidemiological sample. Journal of Affective Disorders. 2010; 125(1-3):350-354. [PubMed: 20226535]

Leibenluft E. Severe mood dysregulation, irritability, and the diagnostic boundaries of bipolar disorder in youths. American Journal of Psychiatry. 2011; 168(2):129-142. [PubMed: 21123313]

Maalouf FT, Porta G, Vitiello B, Emslie G, Mayes T, Clarke G, Wagner KD, Asarnow JR, Spirito A, Keller M, Birmaher B, Ryan N, Shamseddeen W, Iyengar S, Brent D. Do sub-syndromal manic symptoms influence outcome in treatment resistant depression in adolescents? A latent class analysis from the TORDIA study. Journal of affective disorders. 2012; 138(1-2):86-95. [PubMed: 22284022]

Merikangas KR, Cui L, Kattan G, Carlson GA, Youngstrom EA, Angst J. Mania With and Without Depression in a Community Sample of US Adolescents. Archives of General Psychiatry. 2012; 69:943-951. [PubMed: 22566563] 
Mick E, Biederman J, Faraone SV, Murray K, Wozniak J. Defining a developmental subtype of bipolar disorder in a sample of nonreferred adults by age at onset. Journal of Child \& Adolescent Psychopharmacology. 2003; 13(4):453-462. [PubMed: 14977458]

Moreno C, Laje G, Blanco C, Jiang H, Schmidt AB, Olfson M. National trends in the outpatient diagnosis and treatment of bipolar disorder in youth. Archives of General Psychiatry. 2007; 64(9): 1032-1039. [PubMed: 17768268]

Olfson M, Crystal S, Gerhard T, Huang CS, Carlson GA. Mental health treatment received by youths in the year before and after a new diagnosis of bipolar disorder. Psychiatric Services. 2009; 60(8): 1098-1106. [PubMed: 19648198]

Sala R, Axelson DA, Castro-Fornieles J, Goldstein TR, Ha W, Liao F, Gill MK, Iyengar S, Strober MA, Goldstein BI, Yen S, Hower H, Hunt J, Ryan ND, Dickstein D, Keller MB, Birmaher B. Comorbid anxiety in children and adolescents with bipolar spectrum disorders: prevalence and clinical correlates. Journal of Clinical Psychiatry. 2010; 71(10):1344-1350. [PubMed: 20868643]

Stringaris A. Irritability in children and adolescents: a challenge for DSM-5. European Child and Adolescent Psychiatry. 2011; 20(2):61-66. [PubMed: 21298306]

Stringaris A, Cohen P, Pine DS, Leibenluft E. Adult outcomes of youth irritability: a 20-year prospective community-based study. American Journal of Psychiatry. 2009; 166(9):1048-1054. [PubMed: 19570932]

Stringaris A, Santosh P, Leibenluft E, Goodman R. Youth meeting symptom and impairment criteria for mania-like episodes lasting less than four days: An epidemiological enquiry. Journal of Child Psychology and Psychiatry. 2010; 51(1):31-38. [PubMed: 19686330]

Strober M, Carlson G. Bipolar illness in adolescents with major depression: clinical, genetic, and psychopharmacologic predictors in a three- to four-year prospective follow-up investigation. Archives of General Psychiatry. 1982; 39(5):549-555. [PubMed: 7092488]

Taylor L, Faraone SV, Tsuang MT. Family, twin, and adoption studies of bipolar disease. Current Psychiatry Reports. 2002; 4(2):130-133. [PubMed: 11914174]

Van Meter AR, Moreira AL, Youngstrom EA. Meta-analysis of epidemiologic studies of pediatric bipolar disorder. Journal of Clinical Psychiatry. 2011; 72:1250-1256. [PubMed: 21672501]

Vieta E, Suppes T. Bipolar II disorder: arguments for and against a distinct diagnostic entity. Bipolar Disorders. 2008; 10(1 Pt 2):163-178. [PubMed: 18199235]

Wozniak J, Faraone SV, Mick E, Monuteaux M, Coville A, Biederman J. A controlled family study of children with DSM-IV bipolar-I disorder and psychiatric co-morbidity. Psychological Medicine. 2010; 40(7):1079-1088. [PubMed: 19891803]

Yorbik O, Birmaher B, Axelson D, Williamson DE, Ryan ND. Clinical characteristics of depressive symptoms in children and adolescents with major depressive disorder. Journal of Clinical Psychiatry. 2004; 65:1654-1659. [PubMed: 15641870]

Youngstrom EA, Birmaher B, Findling RL. Pediatric bipolar disorder: validity, phenomenology, and recommendations for diagnosis. Bipolar Disorders. 2008; 10(1 Pt 2):194-214. [PubMed: 18199237]

Zimmermann P, Bruckl T, Nocon A, Pfister H, Lieb R, Wittchen H-U, Holsboer F, Angst J. Heterogeneity of DSM-IV major depressive disorder as a consequence of subthreshold bipolarity. Archives of General Psychiatry. 2009; 66(12):1341-1352. [PubMed: 19996039] 


\section{Key Practitioner Messages}

- Bipolar disorder (BP) is a familial illness that usually onsets during adolescence. However, its diagnosis is difficult, especially the identification of episodes and symptoms like grandiosity and elation in young children.

- Most of the discrepancies in the diagnosis of BP in youth are for the subclinical subtypes

- $\quad$ BP is a recurrent illness with frequent syndromal and especially subsyndromal depressive and mixed episodes that significantly affects the psychosocial functioning of the youth.

- Youth with BP-NOS and family history of BP are at high risk to develop BP-I and II.

- Given the existing problems interpreting the symptoms of mania in youth and the overlap with symptoms of comorbid disorders (e.g., ADHD), the prevalence is not well known, but current studies across the globe suggest a prevalence of BP-I of about $1 \%$

- Unrecognized and undertreated carries severe consequences for the normal development of the child. However, a misdiagnosis also carries negative consequences. 
Table 1

Bipolar disorder versus attention deficit hyperactive disorder (ADHD)

(Reproduced from Birmaher, B. New Hope for Children and Adolescents with BP Disorders, New York: Three Rivers Press, a division of Random House, Inc., 2004, with permission)

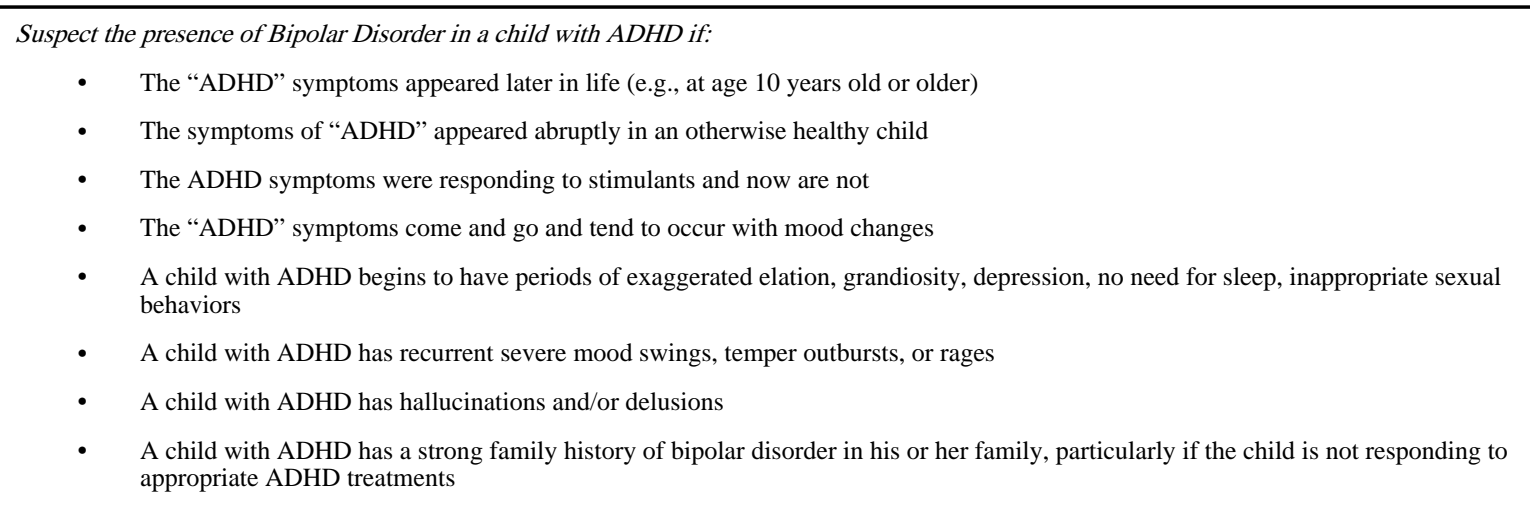

Note: A child may have both ADHD and BP. Moreover, above noted clinical situations may also be due to other psychiatric disorders (e.g., unipolar depression, substance abuse), medical problems (e.g., thyroid problems, seizures, tumors), use of medications (e.g., prednisone), and environmental stressors (e.g., family conflict, chaotic environment, sexual or physical abuse) that may coexist with ADHD. 
Table 2

Bipolar disorder versus behavior disruptive disorder

(Reproduced from Birmaher, B. New Hope for Children and Adolescents with BP Disorders, New York: Three Rivers Press, a division of Random House, Inc., 2004, with permission.)

- If the behavior problems only occur while the child is in the midst of an episode of mania or depression, and the behavior problems disappear when the mood symptoms improve, the diagnoses of oppositional or conduct disorder should not be made.

- If a child has "of and on" oppositional or conduct symptoms or these symptoms only appear when the child has mood problems, the diagnosis of BP (or other disorders such as recurrent unipolar depression or substance abuse) should be considered.

- If the child had oppositional behaviors before the onset of the mood disorders, both diagnoses may be given.

- If a child has severe behavior problems that are not responding to treatment, consider the possibility of a mood disorder (bipolar and non-bipolar depressions), other psychiatric disorder (e.g., ADHD, substance abuse), and/or exposure to stressors.

- If a child has behavior problems and a family history of bipolar, consider the possibility that the child has a mood disorder (unipolar major depression or BP disorder).

- If a child has behavior problems and is having hallucinations and delusions consider the possibility of BP disorder. Also consider the possibility of schizophrenia, use of illicit drugs/alcohol, or medical/neurological conditions. 